Discussion Paper No. 17-070

\title{
Matching Schemes and Public Goods: A Review
}

Raphael Epperson and Christiane Reif

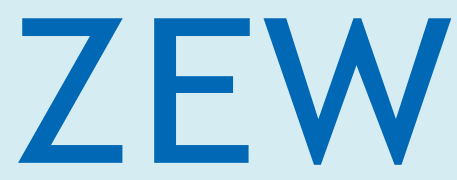

Zentrum für Europäische Wirtschaftsforschung $\mathrm{GmbH}$

Centre for European Economic Research 
Discussion Paper No. 17-070

\title{
Matching Schemes and Public Goods: A Review
}

\author{
Raphael Epperson and Christiane Reif
}

Download this ZEW Discussion Paper from our ftp server:

http://ftp.zew.de/pub/zew-docs/dp/dp17070.pdf

Die Discussion Papers dienen einer möglichst schnellen Verbreitung von neueren Forschungsarbeiten des ZEW. Die Beiträge liegen in alleiniger Verantwortung der Autoren und stellen nicht notwendigerweise die Meinung des ZEW dar.

Discussion Papers are intended to make results of ZEW research promptly available to other economists in order to encourage discussion and suggestions for revisions. The authors are solely responsible for the contents which do not necessarily represent the opinion of the ZEW. 


\title{
Matching schemes and public goods: A review
}

\author{
Raphael Epperson ${ }^{\mathrm{a}^{*}}$ and Christiane Reif ${ }^{\mathrm{b}}$
}

\section{${ }^{a}$ University of Mannheim, Center for Doctoral Studies in Economics; \\ ${ }^{b}$ Centre for European Economic Research (ZEW)}

This version: January 12, 2018

\begin{abstract}
:
Matching schemes, where a party matches the contribution of others, reduce the effective price of a good and aim to foster its demand. We review the empirical literature on the effectiveness of these schemes in the context of public goods, especially in the field of charitable giving. As different measures of effectiveness are used, we classify results according to (i) the level of public good provision, (ii) the amount of individuals' contributions, (iii) the likelihood to give and (iv) the contribution conditional on contributing a positive amount. Generalizing results is challenging, since context specific factors matter. Predominantly, a match is found to create a significant increase in public good provision without crowding out individuals' contributions, while the effect on the likelihood of giving and contribution condition on contributing a positive amount is nonnegative. The discussion reveals several avenues for future research, as putting stronger emphasizes on long term effects, public good competition or heterogeneity in responses.
\end{abstract}

JEL-Code: D01, D64, H41, L31

Keywords: literature review, matching schemes, charitable giving, public goods

\section{Acknowledgements:}

We are grateful to Wolfgang Habla, Martin Kesternich, Florian Landis and Dirk Rübbelke for their comments on a previous draft. The financial support by the German Federal Ministry of Education and Research (FKZ 01UT1411A) is gratefully acknowledged. Further details can be obtained from http://kooperationen.zew.de/en/intrans/home.html. 


\section{Introduction}

Although not always apparent, our everyday life offers numerous examples of matching schemes: In the field of charitable giving, campaigns stating "we double your donation” are used to encourage contributions while in the private sector, supermarkets try to stimulate consumption with advertising messages like "buy one get one free”. Similarly, parents use this mechanism to steer their children towards saving money, when promising "for each dollar you save, you get an additional dollar from us”. The underlying idea of the mechanism is to cut the effective price of the corresponding good by offering a subsidy. If the good under consideration is an ordinary good, such price reductions are expected to increase the provision or consumption level and, in case of a public good, can help to facilitate voluntary public good provision.

In this literature review, we focus on the experimental findings about the effect of matching mechanisms on voluntary public good provision, as matching mechanism offer nongovernmental institutions the possibility to trigger public good contributions without a regulating central authority. Empirical studies are mainly situated in the charitable giving context, a special case of voluntary public good provision (see Vesterlund 2016 based on Becker 1974), which does not necessarily correspond to that of a pure public good. Matching mechanisms are of particular interest for fundraisers to increase donations. A wide definition of matching would subsume mechanisms sharing the costs of public good provision (Guttman 1987). In the charitable giving context, a narrower view is taken up to differentiate between rebates and matches (see e.g. Eckel \& Grossman 2003; Davis et al. 2005). ${ }^{1}$ Rebates return part of the donated money to the donor while passing the entire donation amount to the charity. Matches supplement the donated money and both the donation and the match are passed to the charity.

Our emphasis lies on the effectiveness of matching mechanisms in increasing contributions. In the review, we concentrate on public good experiments testing explicit matching mechanisms and exclude implicit matching as well as mechanisms combined with punishment schemes. Our major contribution is twofold. First, we assess and classify the empirical evidence of matching schemes according to four different measures of effectiveness, while taking into account context specific factors that potentially affect the results. This allows to identify general patterns and examine to which extent different findings in the literature can be explained by varying conditions. By doing so, we include a broad discussion of long term effects and the

\footnotetext{
${ }^{1}$ In this strand of the literature, rebates are commonly defined as being realized without any delay. Therefore, they are strategically equivalent to matches.
} 
effectiveness of matching schemes that go beyond the classical linear structure. Second, we build upon this detailed review to identify research gaps and make suggestions for future research.

A previous literature review by Vesterlund (2016) is related to our review as it provides a comprehensive overview of experimental results on the motives of charitable giving and different fundraising mechanisms aiming to increase giving. Her survey includes a basic summary on matching and rebates with a particular focus on comparing these two. She concludes that based on the resulting level of the public good, matches are more effective than rebates, which is in line with experiments explicitly testing matching versus rebates (Eckel \& Grossman 2003, 2006a, 2006b, 2008, 2017; Davis et al. 2005; Lukas et al. 2010; Bekkers 2015).

In the following section, we briefly describe matching mechanisms in the public good context and introduce the four different measures of effectiveness. Based on this differentiation, we provide the result of the selective literature in section three and discuss long-term effects as well as extended considerations beyond linear matching. Finally, we draw conclusions and highlight opportunities for future research.

\section{Fundamentals of matching schemes}

The underlying idea of matching in the public good context is to facilitate voluntary public good provision by stockpiling the individual's contribution. The strategic nature of such a mechanism is to reduce the effective price of the public good (see e.g. Boadway et al. 1989; Buchholz et al. 2011; Buchholz et al. 2014; Reif et al. 2017). If demand is price elastic and the public good is an ordinary good, which shall be assumed throughout the following review, the level of public good provision will increase.

The empirical literature offers valuable insights about the impact of matching on voluntary public good provision. Especially in the context of charitable giving there is a vast number of empirical analyses. In such settings some party offers to match the individuals' contributions to the public good at a matching rate $m>0$. Based on the matching rate, each individual $i$ decides on her public good contribution, $d_{i}{ }^{2}$ Thus, the effective price of the public good individual $i$ is confronted with depends on the matching rate offered and can be formalized as $p_{i}=1 / 1+m$.

\footnotetext{
${ }^{2}$ While in our literature review we examine matching mechanisms in which some party matches the individuals' contributions, it is also possible to allow each individual to match the contributions of others. This is usually referred to as two-sided matching, in contrast to the previously described one-sided matching. Due to the complexity of such mutual matching, theory as well as empirical studies focus on two player settings in these two-
} 
Although the law of demand predicts a price decrease to weakly increase the demand for the public good, the magnitude of the increase strongly depends on the underlying assumptions, i.e. information on individuals' preferences. Karlan \& List (2007) as well as Huck \& Rasul (2011) discuss how different preferences alter the predicted behavioral response to a match. As these preferences are usually not common knowledge, empirical and especially experimental analyses are necessary to evaluate the effect of matching mechanisms on public good provision.

Since this lack of information also prevents researchers from determining the social optimum, alternative measures - inclusive contributions, checkbook giving, extensive margin, and intensive margin - are used to judge the effectiveness of a matching scheme. In this literature review, we summarize the results of different studies for these outcomes. We use the following definitions and formally summarize them in Table 1 . The effectiveness of matching is captured by comparing the corresponding outcomes across treatments, e.g. match and no match.

A straightforward way to measure the effectiveness of matching is to analyze the provision level of public goods with and without a matching scheme in place. In the charitable giving context, the level of a public good is captured by the amount of money an organization receives including the match payment provided by a third party. We refer to this as inclusive contributions. As control and treatment groups often differ in exact group size, evidence is commonly based on the inclusive contribution per individual.

Although inclusive contributions offer an important measure of effectiveness, fundraisers or policy makers might be specifically interested in the effect on contributions made by individuals excluding the matching payment. In line with Eckel \& Grossman (2008), we refer to this as checkbook giving. As pointed out before, matching is expected to have a non-negative effect on inclusive contributions, but the prediction for checkbook giving is ambiguous. A match might decrease the level of checkbook giving, which is referred to as crowding out of private contributions. As inclusive contributions and checkbook giving are closely linked, we can use the price elasticity with respect to the former to conclude on the latter: a price elasticity of inclusive contributions above -1 indicates crowding out, whereas one below -1 represents crowding in.

While an inclusive contribution depends on checkbook giving, checkbook giving itself aggregates two behavioral responses: (i) the likelihood of contributing, which we refer to as

sided matching approaches (see e.g. Guttman 1978; Buchholz \& Konrad 1995; Andreoni \& Varian 1999; Charness et al. 2007; Bracht et al. 2008). In the following, whenever we talk about matching we refer to one-sided matching. 
extensive margin, and (ii) the contribution conditional on contributing a positive amount denoted as intensive margin or conditional checkbook giving. Therefore, a lack of sensitivity on the level of checkbook giving might be explained by the absence of any behavioral adjustment, or e.g. an increase in the likelihood of contributing paired with a counterbalanced decrease in conditional checkbook giving.

\section{Table 1: Outcomes of interest}

\begin{tabular}{cccc}
$\begin{array}{c}\text { Inclusive } \\
\text { contributions }\end{array}$ & Checkbook giving & Extensive margin & Intensive margin \\
\hline $\begin{array}{c}\text { Level of public good } \\
\text { provision/charity } \\
\text { receipts }\end{array}$ & $\begin{array}{c}\text { Amount provided by } \\
\text { the contributor } \\
\text { (excluding the match) }\end{array}$ & $\begin{array}{c}\text { Likelihood of } \\
\text { contributing a positive } \\
\text { amount }\end{array}$ & $\begin{array}{c}\text { Checkbook giving of } \\
\text { contributors }\end{array}$ \\
$E\left[d_{i}(1+m) \mid m, X_{i}\right]$ & $E\left[d_{i} \mid m, X_{i}\right]$ & $\operatorname{Pr}\left(d_{i}>0 \mid m, X_{i}\right)$ & $E\left[d_{i} \mid m, X_{i}, d_{i}>0\right]$
\end{tabular}

Note: $d_{i}$ is the individual's contribution, $m$ is the matching rate and $X_{i}$ are other factors which might be considered and do not need to be individual specific.

\section{Experimental evidence on the effectiveness of matching schemes}

Although Guttman (1978) defines all forms of voluntary sharing of cost for a collective good as implicit matching, experiments are by and large designed to make matching explicit. The reason is that implicit matching makes it difficult to separate the matching effect from the voluntary public good contribution. In the following, we only consider such explicit matching mechanisms and further exclude schemes with any punishment parameters. This means that subjects learn the matching rate and subsequently decide about their contribution. Thereby, we take the narrow definition of matching, according to which matches are a supplement to the donated money a charity obtains. This selection is based on two reasons: First, the large body of experiments on charitable giving has shaped the narrower definition of matching by explicitly distinguishing rebates from matches and analyzing the behavioral response to each subsidy scheme.

Second, there is already a vast amount of analyses focusing on matching versus rebates (see e.g. Eckel \& Grossman 2003, 2006a, 2006b, 2008, 2017; Davis et al. 2005; Davis 2006; Lukas et al. 2010; Bekkers 2015 or for an overview Vesterlund 2016). A common result of this literature is that matches outperform rebates on the basis of inclusive contributions received by the charity. Due to the persistent difference in results between matches and rebates, pooling is problematic. Therefore, we focus on the effectiveness of matching mechanisms only. 
As charitable giving is an important area in which matching is commonly applied, it is not surprising that empirical evidence is almost exclusively obtained in donation related settings. Based on the different measures of effectiveness introduced above (see Table 1), we discuss the effects of matching mechanisms in the corresponding subsections. In general, subjects can marginally adjust their individual contributions within a certain range. Furthermore, most of the studies subsequently discussed focus on linear matching and compare the effect of matching to a baseline scenario without matching. Deviations from this framework, like non-linear matching schemes, discrete choice settings or donation unrelated frameworks, are explicitly stated. Table 2 in the Appendix supplements the following review by providing an overview about the short-term effect of introducing matching estimated by the selective literature. As in the review below, in Table 2 we differentiate between four measures of effectiveness and take special features of settings into account.

\subsection{Inclusive contributions}

In line with the theoretical prediction, laboratory experiments suggest a positive effect on inclusive contributions (Eckel \& Grossman 2003, 2006b; Davis et al. 2005; Davis 2006; Lukas et al. 2010). All these studies are based on some form of a modified dictator game, in which subjects allocate money between themselves and a chosen or pre-determined charity. Each individual faces several donation decisions on a single sheet, differing in whether matching is offered and to which extent the individual's contribution is matched by the experimenter. As these studies are primarily concerned with a comparison of match and rebate, decision sheets sometimes contain both frames (Eckel \& Grossman 2003; Davis et al. 2005; Davis 2006).

To quantify the magnitude of the effect, one might take a look at the average inclusive contributions across different treatment groups. For example, Davis et al. (2005) find that implementing a 0.5 match increases inclusive contributions by about $62 \%$ when individuals are endowed with \$8, which is close to the percentage increase found by Davis (2006) for the same matching rate in a different setting. We calculate the implied price elasticity of inclusive contributions to be -1.19 , which indicates crowding in. Davis et al. (2005) and Davis (2006) additionally consider a matching rate of 1, while Eckel \& Grossman (2003, 2006b) and Lukas et al. (2010) implement matching rates of 0.25, 0.33, and 1. Evidence suggests that, in general, increasing the matching rate increases inclusive contributions, with two studies actually testing for significance (Eckel \& Grossman 2003, 2006b). The corresponding price elasticities amount to -1.07 and -2.6 , respectively. 


\subsection{Checkbook giving}

Price elasticities of inclusive contributions around or below -1 already point towards a zero or positive effect on checkbook giving. Indeed, most studies find a significant increase in checkbook giving due to linear matching (Karlan \& List 2007; Huck et al. 2015; Eckel \& Grossman 2017), while others either find significant effects only for some matching rates and endowments (Davis 2006) or do not find effects significantly different from zero at all (Karlan et al. 2011). Most of this evidence is based on fundraising in the field. For example, Karlan \& List (2007) use a mail-out to former contributors of a non-profit organization implementing matching rates of 1,2 , and 3 . Comparing the average checkbook giving per solicitation in matching treatments to the one in the control group reveals a significant positive increase by 19 per cent. ${ }^{3}$ However, the levels of average checkbook giving under the considered matching rates do not differ significantly. Such a lack of responsiveness of checkbook giving to the magnitude of matching is supported by Bekkers (2015) for matching rates of 0.5 and 1 . Furthermore, Lukas et al. (2010) conduct a laboratory experiment with matching rates of 0.25 , 0.33 , and 1 , and two different endowment levels, in which only a matching rate increase from 0.33 to 1 with an endowment of $\$ 10$ is found to create a significant increase. Other studies considering matching rates not greater than 1 do not test for significance but their descriptive statistics rather suggest no additional effect of increasing the matching rate (Eckel \& Grossman 2003; Davis 2006; Karlan et al. 2011).

The effect of matching on checkbook giving and thus inclusive contributions might not solely evolve due to a change in the effective price. As emphasized by Huck \& Rasul (2011), matching possibly creates a signal for potential contributors, e.g. that the non-profit organization is worth supporting. If in a between-subject design people in the control treatment are simply asked for donations, the estimated effect on checkbook giving will include both a price and a signaling effect. To exclude the latter, it would be necessary to send a similar signal in the control treatment, e.g. by mentioning a lead donor who has already provided some funding for the project or using a within subject design. Indeed, Gneezy et al. (2014) as well as Huck et al. (2015) identify a significant positive effect of linear matching on checkbook giving if a control treatment without lead donor is used, while finding no significant effect with a lead donor baseline. However, Adena \& Huck (2017) use a lead donor treatment as baseline and still find

\footnotetext{
${ }^{3}$ The effect is only significant if observations from treatments with different matching rates are pooled in the regression. If instead checkbook giving is regressed on a treatment dummy as well as the interaction of the treatment dummy and a dummy on the matching rate (2 or 3), none of these regressors are significant. The same holds with respect to the results for the extensive margin presented later on.
} 
a significant increase of about 2.4\% in average checkbook giving per solicitation letter sent, when introducing a 1:1 match. Together with the evidence on matches being superior to equivalent rebates (Eckel \& Grossman 2003, 2006a, 2006b, 2008, 2017; Davis et al. 2005; Lukas et al. 2010; Bekkers 2015), this suggests that in practice a matching response might not be solely driven by a decrease in the effective price.

As a non-negative effect on checkbook giving implies an increase in inclusive contributions when matching is introduced or the matching rate is raised, findings are in line with the evidence on inclusive contributions previously discussed.

\subsection{Extensive margin}

With respect to the extensive margin, it is difficult to identify a general pattern. Huck \& Rasul (2011) as well as Karlan et al. (2011) do not find a significant effect of matching rates no greater than 1 on the aggregate, while Karlan \& List (2007) report a significant increase in the extensive margin by 0.4 percentage points, when pooling data on matching rates of 1,2 and $3 .^{4}$ Furthermore, Eckel \& Grossman (2017) identify a significant positive impact for a matching rate of $1 / 3$ (8.4 percentage points), but fail to do so for a matching rate of 0.25 . Thus, it seems that a positive effect on the extensive margin might only arise if the matching rate is sufficiently large. Gneezy et al. (2014) offer additional evidence on a positive impact using a matching rate of 1 , but with a special setting feature in place, determining that the lowest positive donation possible amounts to $\$ 20$.

As previously discussed, a lead donor baseline might be used to eliminate the signaling effect of matching. Gneezy et al. (2014) do so and find that under these conditions the impact of matching on the extensive margin vanishes. This lack of response is in line with Huck \& Rasul (2011) but in contrast to Adena \& Huck (2017), who find a significant positive impact of 0.6 percentage points. ${ }^{5}$

A crucial aspect, not only when considering the extensive margin, is that effects might be heterogeneous. For example, Eckel \& Grossman (2008) send out mails to raise funds for a nonprofit organization which include matching rates of either 0.25 or $1 / 3$. Compared to a baseline without a lead donor, the extensive margin of regular contributors with a membership of the organization is significantly lower when matching is in place, while such an effect cannot be identified for other types of individuals. Although not tested for significance, the descriptive

\footnotetext{
${ }^{4}$ This effect is substantial since the likelihood of contributing in the control group is $1.8 \%$.

${ }^{5}$ This effect is substantial since the likelihood of contributing in the lead donor control treatment is $1.51 \%$.
} 
statistics suggest that this impact is strong enough to decrease average checkbook giving of the particular subgroup. This finding constitutes an exception of the previously discussed results stating that on the aggregate we do not observe crowding out of checkbook giving. Interestingly, the result that more active subjects react negatively to the match might not hold in general. Karlan \& List (2007) find no considerable difference in their sample of prior donors between those donors that have not provided funds in the year of the experiment yet and those that have. Karlan et al. (2011) on the other hand detect a negative impact on the extensive margin for the former but a significantly higher one for the latter, ${ }^{6}$ which also holds true with respect to checkbook giving. Furthermore, the heterogeneous response is primarily driven by the higher matching rate of $1 / 3$. This emphasizes that a lack of impact on the aggregate might be the result of substantial heterogeneous effects canceling each other out.

Moreover, Karlan \& List (2007) emphasize a spatial heterogeneity based on whether the majority of people in a state voted for George W. Bush in the 2004 presidential election. In the states that voted for him, the match has a significant positive impact on the likelihood of contributing, while for the rest no significant effect occurs. The importance of political aspects in this context might be particularly driven by the fact that the involved non-profit organization is a political one. Nevertheless, all three studies highlight why heterogeneity in responses is worth considering and that exclusively focusing on the aggregate might lead to missing crucial response patterns.

Meier (2007) investigates the donation behavior of students in the field, focusing on a slightly different measure. At the time of paying the tuition fees, each student has to decide whether to donate to no fund, a single fund, or two funds. Each decision is associated with a fixed amount of money. Offering a matching rate of 0.25 or 0.5 for contributing to both funds, pooling the data for these into a single treatment, and taking into account pre-treatment differences reveals a significant increase in the likelihood of contributing to both funds. However, if the two matching treatments are considered separately in a logit regression, the lower matching rate is not found to have a significant coefficient while the higher matching rate does. Furthermore, the two coefficients are not statistically different. While in Meier (2007) subjects have three options to choose from, the contribution decision in Kesternich et al. (2016) is binary. Customers of a German long-distance bus operator have the opportunity to offset their carbon

\footnotetext{
${ }^{6}$ As a result, the point estimate of the effect on the extensive margin of recent donors is positive. However, a test on whether this positive effect is significantly different from zero is not provided.
} 
emissions at a pre-determined price when purchasing tickets. ${ }^{7}$ If a match is in place, the company itself offsets an additional amount of carbon emissions corresponding to the match rate offered. A matching rate of $1 / 3$ creates no effect, but a matching rate of 1 is found to significantly increase the likelihood of offsetting compared to the control group, which results in a significant increase in checkbook giving. Interestingly, a further increase in the matching rate from 1 to 3 does not generate any additional impact, confirming the finding of Karlan \& List (2007) that an increase in the matching rate above one neither significantly affects checkbook giving nor the extensive margin.

\subsection{Intensive margin}

As with the analysis of checkbook giving, the evidence on the intensive margin seems to depend on whether or not a signaling effect is included. Compared to a baseline without lead donor, the intensive margin exhibits a non-negative response: Karlan \& List (2007) do not find a significant impact, while Huck \& Rasul (2011) find a significant increase of 35.9\% due to a 0.5 match, but an insignificant one in case of a match of 1. Again, Eckel \& Grossman (2008) emphasize the relevance of heterogeneity. They show that decreasing the effective price due to matching raises only the intensive margin of continuous members, with the corresponding price elasticity amounting to -0.099 .

If instead a lead donor control group is used, the effect becomes negative (Huck \& Rasul 2011; Adena \& Huck 2017). The magnitude of a match of 1 ranges from a 24\% decrease in Adena \& Huck (2017) to a 35\% decrease in Huck \& Rasul (2011). Gneezy et al. (2014), in contrast, do not find a significant effect when using a lead donor treatment, but estimate a significant positive one with a simple contribution decision as control. However, the fact that potential donors can only choose between three different donation amounts might explain this difference.

\subsection{Long-term effect}

So far, we have focused on the effect of matching on immediate contribution decisions. What about long-term consequences, especially if the matching offer is subsequently removed? A negative long-run effect might arise from intertemporal substitution or a persistent reduction of intrinsic motivation; whereas habit formation potentially keeps contributions at a high level if they have been increased by matching in the first place (Meier 2007). Studying the donation decision students regularly face when paying their tuition fees, Meier (2007) finds a negative

\footnotetext{
${ }^{7}$ As the authors point out, the contribution decision is directly linked to a private consumption choice, which rather makes it an impure public good.
} 
effect of matching on average checkbook giving after the matching offer has been removed. This impact is strong enough to outweigh any positive effect observed in the matching period, leading to an overall negative but insignificant point estimate for the net effect of matching on checkbook giving. In contrast, Karlan et al. (2011) find no effect of matching on average checkbook giving during treatment but an increase in checkbook giving in the six subsequent months. As pointed out by the authors, this result should be treated with caution, since the timing of the study might be crucial and significance diminishes as soon as a logarithmic specification is used. Kesternich et al. (2016) identify a persistent effect of matching compared to the control group. For repeated bookings with the match still in place as well as for subsequent bookings in a period where the match is removed, the treatment group facing a match of 1 has a significantly higher extensive margin and checkbook giving. However, this neither holds for a match of $1 / 3$ nor 3 . While these studies focus on contributions to a public good which was previously matched, Bekkers (2015) investigates long-term consequences for the provision level of a public good which is related to the one previously matched. Individuals complete an online survey and allocate their reward between themselves and to one of three health charities. Looking at their giving behavior in the context of a tsunami relief campaign nine months later reveals no significant difference in contributions between those which were matched and those which were not.

\subsection{Extended considerations}

In the following, we shift our focus back to short-term impacts. As pointed out above, general features of the setting might heavily influence the effectiveness of matching. Karlan et al. (2011) test an alternative representation in which the matching rate of $1 / 3$ is indicated as $\$ 25$ for each $\$ 75$ donated. It turns out that this negatively affects checkbook giving as well as the likelihood of donating. A similar alternative representation of the match of 1 as $\$ 25$ for each \$25 donated does not create any significant effect. Neither stating a matching limit nor using sample donations to illustrate a match appear to be significant (Karlan \& List 2007). Highlighting the urgency does not affect matching responses (Karlan et al. 2011).

Although the major part of the literature focuses on linear matching, alternative forms are considered as well. The mechanism in Meier (2007) can be interpreted as threshold matching, since individuals' checkbook giving is only matched if they donate the fixed amount to both funds. Huck et al. (2015) introduce a different kind of threshold matching, in which individuals are only matched by a rate of 1 if they give at least $\$ 50$. This particular setting significantly increases the likelihood of contributing compared to a lead donor treatment. At the same time, 
however, it negatively affects the intensive margin. On the aggregate, average checkbook giving per solicitation remains unaffected. The performance of this matching scheme does not substantially differ from a simple linear match of 1 already analyzed by Huck \& Rasul (2011), mainly because the threshold is below what potential donors give anyways. Another matching type investigated by Huck et al. (2015) consists of a fixed gift of \$20 for any positive donation. Unsurprisingly, this significantly increases the extensive margin while heavily decreasing the intensive one. In contrast to the threshold match, the latter effect outweighs the increase in the extensive margin, such that average checkbook giving significantly decreases. The data suggest that the checkbook giving under this matching mechanism is the lowest compared to the threshold match, a matching rate of 1 or 0.5 , lead donor, and no lead donor baseline. However, the impact of both matching schemes is likely to heavily depend on the threshold at which the match or gift is offered. A counterfactual simulation makes the authors conclude that a charity is best off, if it simply announces a lead donor. If the charity is forced to use the lead donor's money in a matching scheme, they suggest using a fixed matching gift for a strictly positive threshold. However, it is worth noting that the structural model used for the counterfactual simulations over-predicts particularly the checkbook giving for fixed gift matching.

Another matching alternative is presented in Meer (2017), who investigates daily data from an online fundraising platform. Projects that satisfy certain observable criteria receive a match of 1 from partners of the website or an "Almost Home” match, in which all of the needed funds are provided by a partner organization as long as the last $\$ 100$ are raised by private donors. This represents a cumulative matching threshold for all potential donors. In a pooled analysis of both schemes, matching is found to significantly increase the likelihood of receiving a donation on a given day (by 0.76 percentage points, with a baseline of 3 percentage points), while having a slightly negative effect on the checkbook giving received per day, conditional on receiving a positive amount. As a result, average checkbook giving is raised by $2.8 \%$. The field experiment by Meer (2017) emphasizes that the public good does not need to be linear. It might have some threshold which needs to be reached as otherwise money is returned.

Rondeau \& List (2008) investigate matching in the context of threshold public goods using a laboratory and a field experiment. In the laboratory experiment, they compare a match of 1 with a threshold public good at $\$ 45$ to a lead donor announcement of $\$ 22.5$ and simple no matching settings with varying thresholds ( $\$ 45, \$ 22.5)$. A crowding-out effect in checkbook giving due to matching is apparent relative to no matching. However, it loses significance when a lead donor baseline is used. This is at odds with previous findings in the context of linear public 
goods, in which using a lead donor control corrected estimates rather downwards and the lead donor treatment outperformed the no lead donor control. These differences do not persist in the field experiment. A match of 1 in a mail-out to Sierra Club members with a comparable setup as in the laboratory creates a more severe decrease in checkbook giving when using a lead donor baseline and the lead donor treatment acquires the highest checkbook giving. Although not tested for significance, the point estimate is negative (with and without lead donor), still differing from the predominantly non-negative effects on checkbook giving in the linear public good case. Nevertheless, we cannot be sure that this difference is driven by the design of the public good, as (i) some subgroups in the linear case were identified to be negatively affected, and (ii) we do not know whether the point estimates are significantly different from zero.

\section{Discussion and conclusion}

Matching mechanisms are applied frequently - especially in fundraising campaigns - making their effectiveness an object of particular interest. While the empirical literature in this context is extensive, especially the one discussing experiments on charitable giving, different approaches and surrounding conditions affect the comparability of results. The selective literature review at hand classifies results according to four measures of effectiveness, used to offer a clearer picture and to allow a more diversified assessment of the matching approach. Being as general as possible, a linear match increases the level of public good provision commonly with a price elasticity no larger than -1 . Results on checkbook giving are less distinct but reveal a tendency of no or a rather positive effect on the aggregate, driven by a non-negative effect on the likelihood of giving (extensive margin) and average contribution conditional on contributing a positive amount (intensive margin).

Nevertheless, results, and therefore recommendations, are context specific. A threshold public good might turn a non-negative effect on checkbook giving into a negative one, crowding out the individual's contribution (see Rondeau \& List 2008). Additionally, responses can differ across target groups (e.g. a negative effect on the extensive margin of continuous members in Eckel \& Grossman 2008), which can lead to wrong conclusions about the effectiveness when only the aggregate level is considered (Karlan et al. 2011). Empirical evidence on heterogeneous effects is rare and offers opportunities for future research. In particular, it would be interesting to see whether the response of certain subgroups (like more involved individuals) follows a general pattern. 
Although a match is expected to be effective because it decreases the effective price of a public good, the empirical literature suggests that this might not be the single driver. Especially in field experiments with between-subject designs the match potentially sends a signal of the good being worth contributing to (Huck \& Rasul 2011). Including a lead donor control to isolate the price effect generally corrects estimates downwards. However, this does not urge future research to use a lead donor as baseline. It is rather a question of which comparison is more interesting from one's own perspective. Pertaining to estimate the price elasticity of giving, it might indeed be important to use a lead donor baseline, as this allows eliminating (or at least mitigating) a signaling effect of matching (Huck \& Rasul 2011). Another potential source of distortion when estimating the price elasticity of giving is that not all treated subjects might be aware of the match offer (Eckel \& Grossman 2017), especially in field experiments. If the subject's perceived price of giving differs from the one assumed by the researcher, price elasticity estimates are biased. Eckel \& Grossman (2017) account for this by requiring individuals to check a box to receive the offered match. When only those checking the box are treated as receiving the match and facing the reduced effective price, the price elasticity estimate increases in absolute terms. One direction for future research is to shed more light on the extent to which the effect of matching is actually driven by the price reduction, helping to understand how observed behavioral responses come about.

A crucial remark is that even if linear matching raises charity income or, more general, public good provision, it might not be the best strategy at hand. First, matching does not need to be linear. Other matching forms like threshold matching could offer additional advantages, though they need to be designed very carefully (Huck et al. 2015). Future research can help to extend the available matching forms, understand their benefits as well as drawbacks, and eventually create generally valid guidelines about when to use which form.

Second, the money of the third party might be used in a different way, e.g. as an unconditional and announced lead donor gift. As pointed out above, comparing the match to a lead donor treatment generally corrects effects downwards. Although checkbook giving in the matching condition never falls significantly below that of the lead donor treatment (Gneezy et al. 2014; Huck et al. 2015; Adena \& Huck 2017), point estimates speak in favor of a lead donor in two of three studies (Gneezy et al. 2014; Huck et al. 2015). Another promising alternative strategy might be to use the money of the third party to cover a charity's overhead costs (Gneezy et al. 2014). 
Third, potential business stealing due to matching needs to be considered, at least on the broader level. For example, an individual might decide to increase the contribution to one good at the expense of investing in another. Meer (2017) finds that the number of matched competitors positively affects checkbook giving, although the magnitude is very small. Even an intertemporal cannibalization is rejected, since the average daily number of competitors over the previous sixty days has a small but significantly positive effect on checkbook giving. However, this is only a single study in a very specific setting of school projects trying to raise funds on an online platform. Further evidence on how matching affects giving to competing charities is needed.

Finally, future research should put more emphasize on the long-term impact of a matching mechanism in terms of repeated treatment (see Kesternich et al. 2016) or after the match has been removed (see Meier 2007; Bekkers 2015; Kesternich et al. 2016). Only a few studies take the long-term perspective into account. A more detailed analysis extending the observation period could help to verify how matches affect individuals' long-term contribution decisions: Can matches form habits and keep contributions to the public good on a higher level or does matching rather cause harm due to intertemporal substitution or motivational crowding?

While we have learned a lot about matching from the empirical literature, many questions, as indicated above, remain open. Closing these research gaps not only elevates our level of understanding, but enables practitioners to improve the design of fundraising schemes and mechanisms to foster voluntary public good provision. 


\section{References}

Adena M, Huck S. 2017. Matching donations without crowding out? Some theoretical considerations, a field, and a lab experiment. J. Public Econ. 148:32-42

Andreoni J, Varian H. 1999. Preplay contracting in the prisoners' dilemma. Proc. Natl. Acad. Sci. 96(19):10933-38

Becker GS. 1974. A theory of social interactions. J. Polit. Econ. 82(6):1063-93

Bekkers R. 2015. Replication in experimental economics. Res. Exp. Econ. 18(18):41-13

Boadway R, Pestieau P, Wildasin D. 1989. Tax-transfer policies and the voluntary provision of public goods. J. Public Econ. 39:157-76

Bracht J, Figuières C, Ratto M. 2008. Relative performance of two simple incentive mechanisms in a public goods experiment. J. Public Econ. 92(1-2):54-90

Buchholz W, Cornes R, Rübbelke D. 2011. Interior matching equilibria in a public good economy: An aggregative game approach. J. Public Econ. 95:639-45

Buchholz W, Falkinger J, Rübbelke D. 2014. Non-governmental public norm enforcement in large societies as a two-stage game of voluntary public good provision. J. Public Econ. Theory. 16(6):899-916

Buchholz W, Konrad KA. 1995. Strategic transfers and private provision of public goods. J. Public Econ. 57:489-505

Charness G, Fréchette GR, Qin C-Z. 2007. Endogenous transfers in the Prisoner’s Dilemma game: An experimental test of cooperation and coordination. Games Econ. Behav. 60(2):287-306

Davis DD. 2006. Rebate subsidies, matching subsidies and isolation effects. Judgm. Decis. Mak. 1(1):13-22

Davis DD, Millner EL, Reilly RJ. 2005. Subsidy schemes and charitable contributions: A closer look. Exp. Econ. 8(2):85-106

Eckel CC, Grossman PJ. 2003. Rebate versus matching: Does how we subsidize charitable contributions matter? J. Public Econ. 87(3-4):681-701 
Eckel CC, Grossman PJ. 2006a. Do donors care about subsidy type? An experimental study. In Experiments Investigating Fundraising and Charitable Contributors, Vol. 11, pp. 157-75. Emerald Group Publishing Limited

Eckel CC, Grossman PJ. 2006b. Subsidizing charitable giving with rebates or matching: Further laboratory evidence. South. Econ. J. 72(4):794-807

Eckel CC, Grossman PJ. 2008. Subsidizing charitable contributions: A natural field experiment comparing matching and rebate subsidies. Exp. Econ. 11(3):234-52

Eckel CC, Grossman PJ. 2017. Comparing rebate and matching subsidies controlling for donors’ awareness: Evidence from the field. J. Behav. Exp. Econ. 66:88-95

Gneezy U, Keenan EA, Gneezy A. 2014. Avoiding overhead aversion in charity. Science. 346(6209):632-35

Guttman JM. 1978. Understanding collective action: Matching behavior. Am. Econ. Rev. 68(2):251-55

Guttman JM. 1987. A Non-Cournot model of voluntary collective action. Economica. 54:119

Huck S, Rasul I. 2011. Matched fundraising: Evidence from a natural field experiment. $J$. Public Econ. 95(5-6):351-62

Huck S, Rasul I, Shephard A. 2015. Comparing charitable fundraising schemes: Evidence from a natural field experiment. Am. Econ. J. Econ. Policy. 7(2):326-69

Karlan D, List JA. 2007. Does price matter in charitable giving? Evidence from a large-scale natural field experiment. Am. Econ. Rev. 97(5):1774-93

Karlan D, List JA, Shafir E. 2011. Small matches and charitable giving: Evidence from a natural field experiment. J. Public Econ. 95(5-6):344-50

Kesternich M, Löschel A, Römer D. 2016. The long-term impact of matching and rebate subsidies when public goods are impure: Field experimental evidence from the carbon offsetting market. J. Public Econ. 137:70-78 
Lukas I, Grossman PJ, Eckel CC. 2010. Preference or confusion: Understanding the differential impact of rebate and matching subsidies. Working Paper Indiana University. Indianapolis, IN

Meer J. 2017. Does fundraising create new giving? J. Public Econ. 145:82-93

Meier S. 2007. Do subsidies increase charitable giving in the long run? Matching donations in a field experiment. J. Eur. Econ. Assoc. 5(6):1203-22

Reif C, Rübbelke D, Löschel A. 2017. Improving voluntary public good provision through a non-governmental, endogenous matching mechanism: experimental evidence. Environ. Resour. Econ. 67(3):559-89

Rondeau D, List JA. 2008. Matching and challenge gifts to charity: Evidence from laboratory and natural field experiments. Exp. Econ. 11(3):253-67

Vesterlund L. 2016. Using experimental methods to understand why and how we give to charity. In Handbook of Experimental Economics, pp. 91-151 


\section{Appendix}

\section{Table A1: Overview on short-term effects of one-sided matching experiments}

\begin{tabular}{|c|c|c|c|c|c|c|c|c|c|}
\hline Paper & $\begin{array}{l}\text { Lab/ } \\
\text { Field }\end{array}$ & $\begin{array}{c}\text { Between } \\
\text { Subject } \\
\text { Design }\end{array}$ & $\begin{array}{c}\text { Lead } \\
\text { Donor } \\
\text { Control } \\
\end{array}$ & $\begin{array}{c}\text { Matching } \\
\text { Rates }\end{array}$ & $\begin{array}{c}\text { Inclusive } \\
\text { Contributions }\end{array}$ & $\begin{array}{c}\text { Checkbook } \\
\text { Giving }\end{array}$ & $\begin{array}{l}\text { Extensive } \\
\text { Margin } \\
\text { (pp) }\end{array}$ & $\begin{array}{l}\text { Intensive } \\
\text { Margin }\end{array}$ & Comments \\
\hline Adena \& Huck (2017) & Field & yes & yes & 1 & & $+2.4 \% * *$ & $+0.6 * *$ & $-23.7 \% * *$ & \\
\hline Bekkers (2015) & Field & yes & no & $\begin{array}{c}0.5 \\
1\end{array}$ & & $\begin{array}{l}+57.5 \% \mathrm{~d}^{\mathrm{d}} \\
+89.7 \% \mathrm{~d}^{\mathrm{d}}\end{array}$ & $\begin{array}{l}+15.9^{\mathrm{d}} \\
+22.0^{\mathrm{d}}\end{array}$ & $\begin{array}{l}+8.4 \%^{\mathrm{d}} \\
+16.5 \%{ }^{\mathrm{d}}\end{array}$ & $\begin{array}{l}\text { The Checkbook giving and } \\
\text { intensive margin results presented } \\
\text { are based on fractions of the } \\
\text { endowment passed, since } \\
\text { endowments differ across } \\
\text { individuals, who get money for } \\
\text { answering a survey. }\end{array}$ \\
\hline Davis et al. (2005) & Lab & no & no & 0.5 & $\begin{array}{l}+62.2 \% \mathrm{~d} / \\
+36.1 \% \mathrm{~d} \\
+134.0 \% \mathrm{~d} / \\
+113.3 \%{ }^{\mathrm{d}}\end{array}$ & $\begin{array}{l}+8.0 \% \mathrm{~d} / \\
-8.3 \% \mathrm{~d} \\
+17.0 \% \mathrm{~d} / \\
+6.7 \% \mathrm{o}^{\mathrm{d}}\end{array}$ & & & $\begin{array}{l}\text { Endowment } \$ 8 / \$ 12 \text {. } \\
\text { Tested for significance in Davis } \\
\text { (2006). Results refer to charitable } \\
\text { giving context without extra } \\
\text { information. }\end{array}$ \\
\hline Davis (2006) & Lab & no & no & 0.5 & $\begin{array}{c}+63.3 \% * * * \mathrm{~d} / \\
+57.1 \% * * * \mathrm{~d} \\
{[+62.2 \% * * * \mathrm{~d} /} \\
+36.1 \% * * * \mathrm{~d}] \\
+132.7 \% * * * \mathrm{~d} / \\
+124.5 \% * * * \mathrm{~d} \\
{[+134.0 \% * * * \mathrm{~d} /} \\
+113.3 \% * * * \mathrm{~d}]\end{array}$ & $\begin{array}{c}8.2 \% * \mathrm{~b} / \\
\text { Not sig. } \\
\text { [+8.0\%*b/ } \\
\text { Not sig.] } \\
+17.0 \% * * \mathrm{~b} / \\
12.2 \% * * \mathrm{~b} \\
\text { [+17.2\%**b/ } \\
\text { Not sig.] }\end{array}$ & & & $\begin{array}{l}\text { Reformulates decision problem to } \\
\text { shift focus towards amount the } \\
\text { charity receives. } \\
\text { Endowment } \$ 8 / \$ 12 \text {. } \\
\text { [Data from Davis et al. (2005) } \\
\text { tested for significance.] Using } \\
\text { one-sided t-tests. }\end{array}$ \\
\hline
\end{tabular}




\begin{tabular}{|c|c|c|c|c|c|c|c|c|c|}
\hline Paper & $\begin{array}{l}\text { Lab/ } \\
\text { Field }\end{array}$ & $\begin{array}{c}\text { Between } \\
\text { Subject } \\
\text { Design }\end{array}$ & $\begin{array}{c}\text { Lead } \\
\text { Donor } \\
\text { Control }\end{array}$ & $\begin{array}{l}\text { Matching } \\
\text { Rates }\end{array}$ & $\begin{array}{l}\text { Inclusive } \\
\text { Contributions }\end{array}$ & $\begin{array}{l}\text { Checkbook } \\
\text { Giving }\end{array}$ & $\begin{array}{c}\text { Extensive } \\
\text { Margin } \\
\text { (pp) }\end{array}$ & $\begin{array}{l}\text { Intensive } \\
\text { Margin }\end{array}$ & Comments \\
\hline Eckel \& Grossman (2003) & Lab & no & no & $\begin{array}{c}0.25 \\
0.33 \\
1\end{array}$ & $+32.4 \% \%^{\mathrm{d}, \mathrm{o}}$ & & & & $\begin{array}{l}\text { Primary focus on comparing } \\
\text { rebates and matches. Reported } \\
\text { result is for endowment level } \$ 6 \text {. } \\
\text { Significant effect of decreasing the } \\
\text { effective price due to matching on } \\
\text { inclusive contributions in random } \\
\text { effects tobit model. }\end{array}$ \\
\hline $\begin{array}{l}\text { Eckel \& Grossman } \\
\text { (2006b) }\end{array}$ & Lab & no & no & $\begin{array}{c}0.25 \\
0.33 \\
1\end{array}$ & $\begin{array}{c}+107.9 \% \mathrm{~d} / \\
+123.7 \% \mathrm{~d} / \\
+87.2 \% \mathrm{~d} \\
+115.8 \% \mathrm{~d} / \\
+142.7 \% \mathrm{~d} / \\
+86.3 \% \mathrm{~d} \\
+347.5 \% \mathrm{~d} / \\
+366.4 \% \mathrm{~d} / \\
+287.7 \% \mathrm{~d}^{\mathrm{d}}\end{array}$ & & & & $\begin{array}{l}\text { Endowment } \$ 4 / \$ 6 / \$ 7.5 \text {. } \\
\text { Significant effect of decreasing the } \\
\text { effective price due to matching on } \\
\text { inclusive contributions in tobit } \\
\text { model. }\end{array}$ \\
\hline Eckel \& Grossman (2008) & Field & yes & no & 0.25 & $\begin{array}{l}-33.4 \% \mathrm{~d} / \\
+32.7 \% \mathrm{~d} / \\
+56.5 \% \mathrm{~d} \\
-28.5 \% \mathrm{~d} / \\
+50.9 \% \mathrm{~d} / \\
+13.0 \% \mathrm{~d}\end{array}$ & $\begin{array}{l}-46.7 \% \mathrm{~d}^{\mathrm{d}} / \\
+5.5 \% \mathrm{~d} / \\
+26.1 \% \mathrm{~d} \\
-46.4 \% \%{ }^{\mathrm{d} /} \\
+12.7 \% \mathrm{~d} / \\
-13.0 \% \mathrm{~d}\end{array}$ & $\begin{array}{l}-9.4^{\mathrm{d} /} \\
+0.0^{\mathrm{d} /} \\
+0.1^{\mathrm{d}} \\
-8.8^{\mathrm{d} /} \\
+0.1^{\mathrm{d} /} \\
-0.1^{\mathrm{d} /}\end{array}$ & $\begin{array}{l}\text { Not sig./ } \\
\text { Not sig./ } \\
\text { Not sig. } \\
\text { Not sig./ } \\
\text { Not sig./ } \\
\text { Not sig. }\end{array}$ & $\begin{array}{l}\text { Continuing/ lapsed/ prospect } \\
\text { members. } \\
\text { Considering matching rates pooled } \\
\text { reveals significant decrease in } \\
\text { response rate for continuing } \\
\text { members but not for others. } \\
\text { Regression results identify a } \\
\text { significant negative price elasticity } \\
\text { of the intensive margin for } \\
\text { continuing members (-0.099) but } \\
\text { not for others. }\end{array}$ \\
\hline Eckel \& Grossman (2017) & Field & yes & no & $\begin{array}{c}0.25 \\
1 / 3\end{array}$ & & $\begin{array}{l}+38.6 \%{ }^{\mathrm{d}} \\
+47.4 \% \mathrm{o}^{\mathrm{d}}\end{array}$ & $\begin{array}{l}\text { Not sig. } \\
+8.4^{* *}\end{array}$ & & $\begin{array}{l}\text { Additionally, \$5 was donated by } \\
\text { the researchers for each survey } \\
\text { completed. Significant effect on } \\
\text { checkbook giving, but significance } \\
\text { level not stated. }\end{array}$ \\
\hline
\end{tabular}




\begin{tabular}{|c|c|c|c|c|c|c|c|c|c|}
\hline Paper & $\begin{array}{l}\text { Lab/ } \\
\text { Field }\end{array}$ & $\begin{array}{l}\text { Between } \\
\text { Subject } \\
\text { Design }\end{array}$ & $\begin{array}{c}\text { Lead } \\
\text { Donor } \\
\text { Control }\end{array}$ & $\begin{array}{l}\text { Matching } \\
\text { Rates }\end{array}$ & $\begin{array}{l}\text { Inclusive } \\
\text { Contributions }\end{array}$ & $\begin{array}{l}\text { Checkbook } \\
\text { Giving }\end{array}$ & $\begin{array}{l}\text { Extensive } \\
\text { Margin } \\
\text { (pp) }\end{array}$ & $\begin{array}{l}\text { Intensive } \\
\text { Margin }\end{array}$ & Comments \\
\hline Gneezy et al. (2014) & Field & yes & yes & 1 & & Not sig. & Not sig. & Not sig. & $\begin{array}{l}\text { Individuals can donate nothing, } \\
\$ 20, \$ 50 \text { or } \$ 100 \text {. }\end{array}$ \\
\hline Gneezy et al. (2014) & Field & yes & no & 1 & & $+51.9 \% * * * \mathrm{~d}$ & $+1.05^{* * * \mathrm{~d}}$ & $+15.7 \% * * * \mathrm{~d}$ & $\begin{array}{l}\text { Individuals can donate nothing, } \\
\$ 20, \$ 50 \text { or } \$ 100 \text {. } \\
\end{array}$ \\
\hline \multirow{2}{*}{ Huck \& Rasul (2011) } & \multirow{2}{*}{ Field } & \multirow{2}{*}{ yes } & \multirow{2}{*}{ yes } & 0.5 & & & Not sig. & $-30.1 \% * *$ & \\
\hline & & & & 1 & & & Not sig. & $-35.4 \% * * *$ & \\
\hline \multirow{2}{*}{ Huck \& Rasul (2011) } & \multirow{2}{*}{ Field } & \multirow{2}{*}{ yes } & \multirow{2}{*}{ no } & 0.5 & & & Not sig. & $+35.9 \% * \mathrm{~d}$ & \\
\hline & & & & 1 & & & Not sig. & Not sig. & \\
\hline \multirow{3}{*}{ Huck et al. (2015) } & \multirow{3}{*}{ Field } & \multirow{3}{*}{ yes } & \multirow{3}{*}{ yes } & 0.5 & & Not sig. & & & \multirow{3}{*}{$\begin{array}{l}\text { Results for matching rates } 0.5 \text { and } \\
1 \text { are based on same data as Huck } \\
\text { \& Rasul (2011). Only new insights } \\
\text { reported here. }\end{array}$} \\
\hline & & & & $\begin{array}{l}1 \\
1 \text { above } \\
€ 50\end{array}$ & & $\begin{array}{l}\text { Not sig. } \\
\text { Not sig. }\end{array}$ & $+0.8^{* \mathrm{~d}}$ & $-25.8 \% * * d$ & \\
\hline & & & & $\begin{array}{l}€ 20 \\
\text { threshold- } \\
\quad \text { gift }\end{array}$ & & $-29.2 \% * d$ & $+1.2 * * * \mathrm{~d}$ & $-47.6 \% * * * \mathrm{~d}$ & \\
\hline \multirow{3}{*}{ Huck et al. (2015) } & \multirow{3}{*}{ Field } & \multirow{3}{*}{ yes } & \multirow{3}{*}{ no } & 0.5 & & $+50.2 \% * * d$ & & & \multirow{3}{*}{$\begin{array}{l}\text { Results for matching rates } 0.5 \text { and } \\
1 \text { are based on same data as Huck } \\
\text { \& Rasul (2011). Only new insights } \\
\text { reported here. }\end{array}$} \\
\hline & & & & $\begin{array}{l}1 \\
1 \text { above } \\
€ 50\end{array}$ & & $\begin{array}{l}+37.6 \% * \mathrm{~d} \\
+49.8 \% * * \mathrm{~d}\end{array}$ & Not sig. & $+31.8 \% * * \mathrm{~d}$ & \\
\hline & & & & $\begin{array}{l}€ 20 \\
\text { threshold- } \\
\quad \text { gift }\end{array}$ & & Not sig. & $+1.0^{* * \mathrm{~d}}$ & Not sig. & \\
\hline \multirow{3}{*}{ Karlan \& List (2007) } & \multirow{3}{*}{ Field } & \multirow{3}{*}{ yes } & \multirow{3}{*}{ no } & 1 & $+130.9 \%^{\mathrm{d}}$ & Not sig. & Not sig. & Not sig. & \multirow{3}{*}{$\begin{array}{l}\text { Pooled analysis of matching vs. } \\
\text { control: }+18.9 \% * \text { checkbook } \\
\text { giving, }+0.4^{* * *} \text { extensive margin } \\
\text { and no sig. effect intensive margin. }\end{array}$} \\
\hline & & & & 2 & $+280.2 \%{ }^{\mathrm{d}}$ & Not sig. & Not sig. & Not sig. & \\
\hline & & & & 3 & $+363.9 \%{ }^{\mathrm{d}}$ & Not sig. & Not sig. & Not sig. & \\
\hline
\end{tabular}




\begin{tabular}{|c|c|c|c|c|c|c|c|c|c|}
\hline Paper & $\begin{array}{l}\text { Lab/ } \\
\text { Field }\end{array}$ & $\begin{array}{l}\text { Between } \\
\text { Subject } \\
\text { Design }\end{array}$ & $\begin{array}{c}\text { Lead } \\
\text { Donor } \\
\text { Control } \\
\end{array}$ & $\begin{array}{c}\text { Matching } \\
\text { Rates }\end{array}$ & $\begin{array}{c}\text { Inclusive } \\
\text { Contributions }\end{array}$ & $\begin{array}{c}\text { Checkbook } \\
\text { Giving }\end{array}$ & $\begin{array}{l}\text { Extensive } \\
\text { Margin } \\
\text { (pp) }\end{array}$ & $\begin{array}{l}\text { Intensive } \\
\text { Margin }\end{array}$ & Comments \\
\hline Karlan et al. (2011) & Field & yes & no & $\begin{array}{c}1 / 3 \\
1\end{array}$ & & $\begin{array}{l}\text { Not sig. } \\
\text { Not sig. }\end{array}$ & $\begin{array}{l}\text { Not sig. } \\
\text { Not sig. }\end{array}$ & & $\begin{array}{l}\text { Significant positive effect on } \\
\text { checkbook giving in post- } \\
\text { experiment period. }\end{array}$ \\
\hline Kesternich et al. (2016) & Field & yes & no & $\begin{array}{c}1 / 3 \\
1 \\
3\end{array}$ & $\begin{array}{l}\text { Not sig. } \\
+126,2 \% * * * d \\
+327.9 \% * * * d\end{array}$ & $\begin{array}{l}\text { Not sig. } \\
+13.1 \% * * d \\
\text { Not sig }\end{array}$ & $\begin{array}{l}\text { Not sig. } \\
+4.9 * * * \\
+3.1^{*}\end{array}$ & & $\begin{array}{l}\text { Binary decision of whether or not } \\
\text { to offset carbon emissions from } \\
\text { bus travel. }\end{array}$ \\
\hline Lukas et al. (2010) & Lab & no & no & $\begin{array}{l}0.25 \\
0.33\end{array}$ & $\begin{array}{l}+37.2 \% \mathrm{~d} / \\
+33.1 \% \mathrm{~d} \\
+40.0 \% \mathrm{~d} / \\
+54.2 \% \mathrm{~d} \\
+157.1 \% \mathrm{~d} / \\
+163.0 \%{ }^{\mathrm{d}}\end{array}$ & $\begin{array}{l}\text { Not sig./ } \\
\text { Not sig. } \\
+5.2 \% \mathrm{~d} / \\
+15.9 \% \mathrm{~d} \\
+28.5 \% \mathrm{~d} / \\
+31.5 \% \mathrm{~d}^{\mathrm{d}}\end{array}$ & & & $\begin{array}{l}\text { Endowment } \$ 10 / \$ 20 \text {. } \\
\text { Effect of each matching treatment } \\
\text { on inclusive contributions is } \\
\text { significantly positive in tobit } \\
\text { regression where matching effect } \\
\text { is not allowed to differ by } \\
\text { endowment. }\end{array}$ \\
\hline Meer (2017) & Field & - & - & $\begin{array}{l}1 \\
\text { threshold- } \\
\text { gift }\end{array}$ & & $+2.8 \% * * *$ & $+0.76^{* * *}$ & $-1.5 \% *$ & $\begin{array}{l}\text { Results are based on pooled } \\
\text { analysis of } 1: 1 \text { and threshold gift } \\
\text { match. Units of observation are not } \\
\text { donations of individuals but } \\
\text { fundraising results of different } \\
\text { projects on different days. The } \\
\text { intensive margin is thus the } \\
\text { average effect on the checkbook } \\
\text { giving, received by projects } \\
\text { considering only those day-project } \\
\text { observations with a positive } \\
\text { amount. }\end{array}$ \\
\hline
\end{tabular}




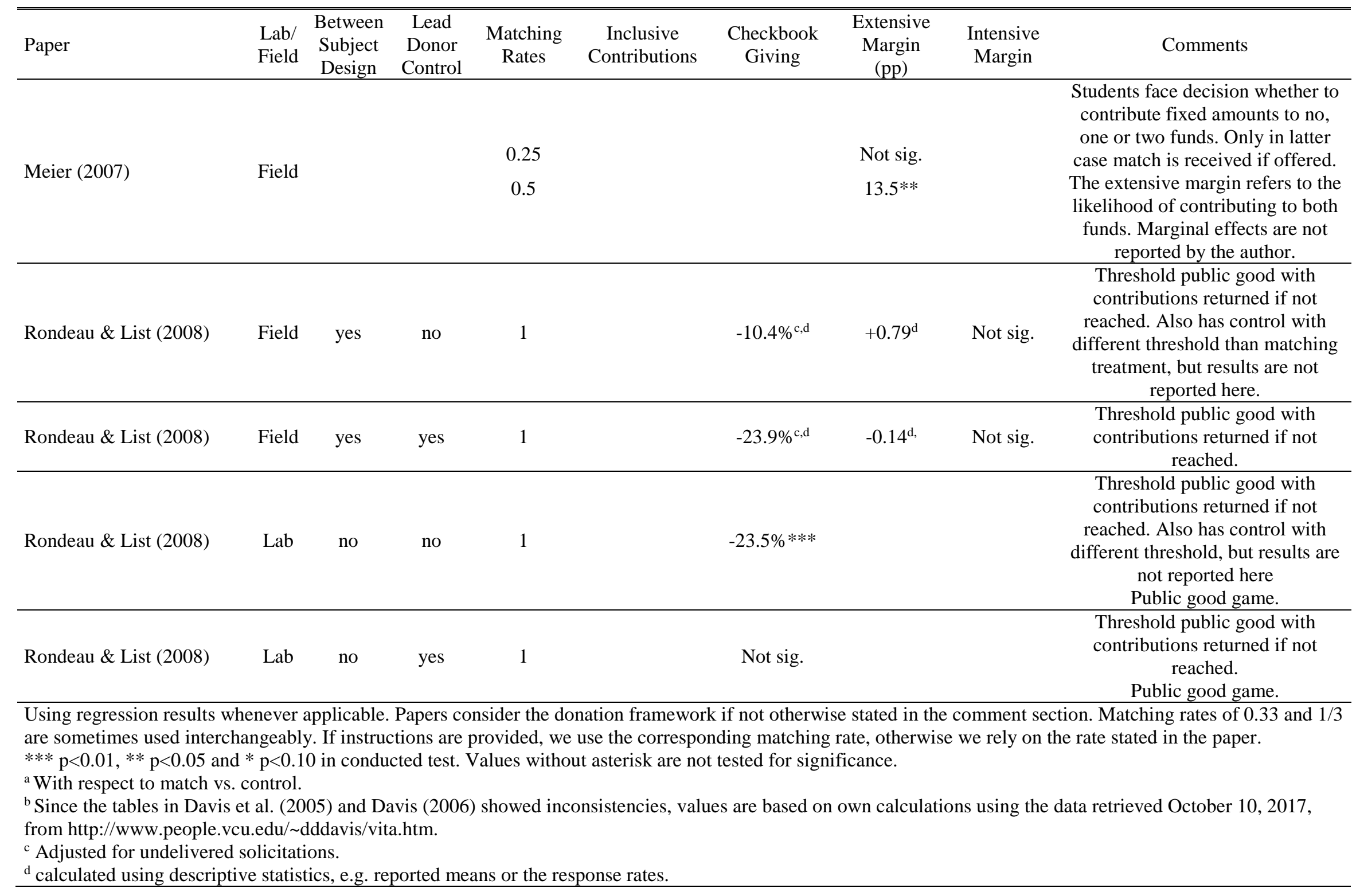

